ANUARIo DE Estudios MEDIEVALES 48/2, julio-diciembre de 2018, pp. 871-900

ISSN 0066-5061

https://doi.org/10.3989/aem.2018.48.2.12

\title{
FESTES, BANQUETS I RITUALS EN LA CONSTRUCCIÓ NAVAL CATALANA DE LA BAIXA EDAT MITJANA*
}

\author{
SHIPBUILDING PARTIES, FEASTS AND RITUALS IN CATALONIA \\ DURING THE LATER MIDDLE AGES
}

\author{
MARCEL PUJOL I HAMELINK \\ Escola Superior de Conservació i Restauració de Béns Culturals de Catalunya \\ http://orcid.org/0000-0003-2876-8233
}

\begin{abstract}
Resum: En el procés de construcció d'una embarcació el ritual més conegut és el de la benedicció. En el nostre estudi volem fer palès que existiren altres cerimònies i actes de caire civil, públic i privat, relacionades amb les diverses etapes prèvies a la seva varada. A partir del moment que es redacta el contracte de construcció fins que s'acaba de construir el buc i es posa a l'aigua es poden arribar a celebrar més de cinc actes, dels quals són molt habituals la festa del romball i la dels anaps. La quantitat d'actes té relació amb la importància del vaixell, ja sigui a causa de les seves dimensions o per qui n'és l'armador.
\end{abstract}

Paraules clau: construcció naval; Baixa Edat Mitjana; Catalunya; ritual; menjar.

Abstract: During the shipbuilding process, the blessing of the ship is the best known tradition. In this study, we aim to point out that there were other ceremonies and acts, both private and public, which could also take place during the process prior to launching the boat. From the moment the building contract was drawn up until the ship's hull was ready, more than five rituals could be performed, such as "la festa del romball" (named after the last piece of the planking) and the ritual of the golden cups. The number of rituals depended on how important the ship and its owner were.

Keywords: shipbuilding; Later Middle Ages; Catalonia; ritual; food.

\section{SUMARI}

1. Personificació del vaixell: el nom propi.-2 Concepció i gestació de l'embarcació.2.1. El contracte de construcció.- 2.2. L'escar.- 2.3. Posar la carena, rodes i quaderna mestra.- 2.4. El romball.- 2.5. La benedicció.- 2.5.1. L'intercanvi de regals: anaps, aixes i marcs.-2.5.2. El gran àpat dels mestres.- 2.6. La varada.- 2.6.1. El banquet de la varada.- 2.7. L'arborar.- 3. En conclusió.- 4. Glossari.- 5. Bibliografia citada.

\footnotetext{
* Aquest treball s'inscriu en el marc del projecte de recerca finançat pel MINECO (Ministerio de Economía y Competitividad) titulat "Tripulacions, armaments, construcció naval i navegació a la Mediterrània medieval" (HAR2013-48433C2-1-P) i forma part de les recerques realitzades pel Grup de Recerca Consolidat per la Generalitat de Catalunya CAIMMed ("La Corona catalanoaraonesa, l'Islam i el món mediterrani medieval", 2017 SGR 1092) dirigits per la Dra. Roser Salicrú i Lluch (Institució Milà i Fontanals, CSIC, Barcelona).

Cómo citar este artículo: Pujol i Hamelink, Marcel (2018), Festes, banquets i rituals en la construcció naval catalana de la Baixa Edat Mitjana, "Anuario de Estudios Medievales" 48/2, pp. 871-900. https://doi.org/10.3989/aem.2018.48.2.12

Copyright: (c) 2018 CSIC. This is an open-access article distributed under the terms of the Creative Commons Attribution 4.0 International (CC BY 4.0) License.
} 


\section{PERSONIFICACIÓ DEL VAIXELL: EL NOM PROPI ${ }^{1}$}

Des de temps immemorials, almenys amb anterioritat als primers documents escrits, les persones s'identifiquen per un nom propi, al qual posteriorment, es va afegir un cognom que podia fer referència a l'ofici, lloc de residència o de procedència, filiació, o malnom de la família. Aquesta identificació personalitzada de l'individu dins del grup es va fer extensiu als animals, donant un nom propi a l'animal més preuat, el gos, o bé aquell que es distingia per alguna raó dins del ramat, i en especial als animals de tir o de muntar, com bous, mules i cavalls.

La personificació dels animals es va estendre a un objecte inanimat, una màquina i medi de transport: el vaixell. De fet a tots ells, no només als més grans o excepcionals, sinó tant als de guerra, de comerç i de pesca, i de la mateixa manera tant grans com petits. Probablement el fet de passar moltes hores, o fins i tot dies, treballant, vivint, menjant i dormint a bord, va crear un lligam estret entre la tripulació i l'embarcació de la qual depenia la seva vida. Només uns centímetres de fusta separaven la tripulació de l'aigua que els podia engolir, per tant s'havia de confiar que aquesta no s'enfonsaria, que resistiria els temporals i els tornaria de nou en terra.

Ara bé, hi ha una diferència clara a remarcar entre les persones, els animals i les embarcacions. Si comparem la vida d'una persona amb el d'una embarcació podem apreciar que les etapes, de fet, coincideixen. La primera seria la concepció, la segona la gestació, la tercera el naixement, la quarta la vida i finalment la cinquena, la mort. En una embarcació la concepció equivaldria al contracte de construcció, la gestació al procés de construcció -des de que el mestre d'aixa posa la quilla fins a que es calafateja-, el naixement seria la benedicció i varada, la vida correspondria al llarg període en que un vaixell compleix amb la funció per a la qual va ser construït, i finalment la mort seria el seu enfonsament o desballestament.

Una persona rep un nom en la tercera etapa, en el moment que neix i se la bateja, moment en que passa a formar part de la comunitat cristiana. Probablement és el moment més important de la vida de tota persona, per aquest motiu queda registrat en un dels tres principals llibres parroquials, el de baptismes. El ritual religiós dut a terme en la benedicció d'una persona també es realitza per a una embarcació. Tot i que el nom d'una embarcació ja es dóna en la primera de les fases, en el contracte de construcció o fase de concepció, que

\footnotetext{
${ }^{1}$ Abreviatures utilitzades: $\mathrm{ACA}=$ Arxiu de la Corona d'Aragó; $\mathrm{ACB}=$ Arxiu de la Catedral de Barcelona; $\mathrm{ACM}=$ Arxiu de la Catedral de Mallorca; ADG = Arxiu Diocesà de Girona; $\mathrm{APP}=$ Arxiu Parroquial de Palamós; ARM = Arxiu del Regne de Mallorca; MR = Mestre Racional; $\mathrm{P}=$ Protocols notarials de Ciutat de Mallorca; $\mathrm{RP}=$ Reial Patrimoni.
} 
equivaldria al nom oficial i administratiu, en la benedicció se li dóna validesa al nom per part de l'Església, se li atorga protecció divina i sovint es registra al llibre de baptismes.

En les embarcacions el moment més important és el de la seva primera varada, el primer contacte amb l'aigua. És l'instant en què es veurà si té una estabilitat correcta, si es dirigeix bé, si té una velocitat adient i bona maniobrabilitat. Un conjunt de qualitats que faran que compleixi bé amb la seva funció, tingui una bona reputació, tant per a qui la fa servir (pescador, comerciant o militar) com al mateix mestre d'aixa que l'ha construït, que ha creat l'objecte, transformant i donant forma a un conjunt de fustes i unint-les entre elles amb elements metàl-lics de fixació. L'objecte tridimensional amb una bona funció nàutica tindrà un prestigi que estimularà l'activitat constructiva del mestre d'aixa i la pervivència i transmissió del seu saber.

Però hi ha embarcacions amb les quals no només es fa una celebració a l'acabar l'embarcació i just abans de varar. Tenim coneixement que en les grans embarcacions construïdes a l'Edat Mitjana i Moderna -tipus nau i galera- $\mathrm{i}$ en àmbits institucionals i senyorials es celebrava no només una festa o ritual, sinó diverses al llarg de tot el procés de construcció. A continuació presentem un llistat de les etapes més importants:

1. El contracte de construcció. En el que l'armador i el mestre d'aixa acorden les característiques de l'embarcació, el seu preu i el nom.

2. L'escar. La primera evidència física de l'existència del que serà l'embarcació, quan el mestre d'aixa prepara l'escar, el lloc on es construirà l'embarcació.

3. La posada de la carena (avui més coneguda com a quilla) de les rodes de proa i popa. Aquestes tres peces defineixen la secció longitudinal principal, i al posar la quaderna mestra sobre la carena es defineix la secció transversal principal del buc de l'embarcació.

4. El romball. Significa que el buc està blanc, acabat, enramat i folrat, llest per a que el calafat intervingui, l'impermeabilitzi i converteixi el buc de blanc en negre.

5. La benedicció. Moment en que l'embarcació es posa sota protecció divina i se li dona un nom propi procedent del santoral.

6. La varada. Etapa important i complicada, en el que per primera vegada tota l'estructura es mourà, desplaçant-se per l'escala de varar fins al mar. No només és un moment dinàmic sinó que l'estructura passa d'un medi terrestre cap a l'aquàtic, cap al medi per a la qual va ser construïda i on es farà evident si podrà complir amb la seva funció.

7. L'arborar. En molts casos, sobretot en les naus, aquestes s'acaben d'arborar un cop el buc ha estat varat. 
La nostra intenció no és remarcar únicament la importància d'una embarcació pel fet de disposar d'un nom propi, o que aquest se li atorgui i quedi registrat documentalment en la fase de concepció, sinó que el procés de concepció i gestació d'una embarcació és realment complex, llarg, amb etapes ben diferenciades, i que es distingeixen cadascuna d'elles amb la celebració de diversos rituals o cerimònies de caràcter laic o religiós.

El moment més important de tot el procés es produeix quan el mestre d'aixa decideix que l'embarcació ja és acabada, llesta per a navegar, quan es realitza la gran cerimònia, multitudinària, de caràcter laic i religiós, que tan sovint contemplem, de la benedicció, varada i primer contacte amb el mar. Però, tal com dèiem, hem pogut observar en la documentació medieval i moderna com hi ha altres etapes en la construcció d'una embarcació que són també importants, que es solen celebrar regularment, i que poden tenir un caràcter íntim o multitudinari, laic o religiós, i de vegades lligat a una embarcació de gran port i construït per part d'una institució com la Generalitat, la ciutat de Barcelona o el rei.

\section{CONCEPCIÓ I GESTACIÓ DE L’EMBARCACIÓ}

\subsection{El contracte de construcció}

La primera etapa de la construcció naval comença amb l'acord entre l'armador i el mestre d'aixa, els quals pacten les característiques de l'embarcació, el preu i el nom. L'acord entre les dues parts pot ser de paraula, amb una encaixada de mans, o bé pot quedar registrat per escrit, aixecant-se acta per part del notari -el contracte de construcció-, fet habitual en la construcció d'embarcacions de port mitjà i gran (com llenys, galeres i naus) ${ }^{2}$. Si la propietat de l'embarcació està repartida entre diferents inversors o socis, anomenats parçoners, també es passa per cal notari, indicant-se al contracte de construcció el nom i la part que aporta cada parçoner.

El mestre d'aixa, amb les ordres donades o les característiques i condicions escrites al contracte, sap quin tipus d'embarcació ha de construir, les seves dimensions i port, la matèria primera que haurà d'utilitzar, el cost que tindrà tant de material com de mà d'obra $i$ els terminis de pagament i execució de l'obra. El mestre d'aixa per la seva banda concebrà mentalment la forma de la embarcació, tant del conjunt com de les seves parts, però també de cadascuna de les peces de fusta que el conformen.

\footnotetext{
${ }^{2}$ Pujol 2012, p. 96.
} 
Aquest sol aplicar un sistema de proporcions per a establir les dimensions generals (llargada de roda a roda, llargada de carena, oberta a coberta, oberta al pla i puntal), les dimensions de l'aparell (arbre, antenes, timó) i dels elements del buc (carena, rodes, madissos, estameneres, cintes, etc). A banda del sistema de proporcions utilitza altres instruments de treball i de concepció de formes, com el gàlib mestre, que junt a la tauleta d'estella i el regle li permeten donar forma a la quaderna mestra i a totes les quadernes compreses entre aquesta i els extrems de proa i de popa, les quals gradualment van modificant la seva forma, perdent amplada al pla $\mathrm{i}$ a coberta $\mathrm{i}$ horizontalitat al pla.

Disposem de bastants documents d'aquest tipus, datats dels segles XIV i XV i localitzats en la seva major part als arxius de protocols notarials de Barcelona i Ciutat de Mallorca.

El primer, redactat a Ciutat de Mallorca l'any 1355, es tracta de la construcció, per part del mestre d'aixa Bernat Mates, d'un lleny d'orla a la Fusteria Antiga, que rebria el nom de Sant Esteve, amb una llargada de 15 goes de carena $(9,71 \mathrm{~m})$ i 12 pams d'oberta ${ }^{3}$. El 4 de setembre de 1357, Bernat Mates, el mateix mestre d'aixa mallorquí, es comprometia a fer la barca descoberta Santa Maria, de 12 goes de carena $(7,77 \mathrm{~m}), 18$ goes de roda a roda, de 8 a 9 pams d'oberta, amb l'eixàrcia i el velam necessari, tot per 50 lliures $^{4}$. El 8 de novembre de 1357, el sobre dit Bernat Mates acordà construir al Fossar Antic dels Jueus la coca Sant Antoni, de 16 goes de carena $(10,36 \mathrm{~m}), 16,5$ pams d'oberta al pla, puntal de 6 pams, i concreta a més el gruix que havia de tenir el corbam d'alzina de 4 dits, mentre l'altra fusta, segurament el folre, seria tota de pi de Mallorca ${ }^{5}$. El 3 d'abril de 1361, Bernat Mates, de nou, acordà amb el mercader Berenguer Llobet construir al Moll Vell una coca que es diria Sant Antoni, la qual havia de fer 16 goes de carena (10,36 m), 7 pams al pla, 20 pams a l'oberta, a més d'especificar algunes de les peces com les dues vies d'escoes que havia de tenir per banda, el paramitjal, la paramola, corbam d'alzina, dragant, etc. Tot per un preu de 115 reials d'or, que es desglossaren en 90 per a la feina i 20 per a la fusta, els 5 reials que falten no sabem si eren un avançament o anaven destinats a altres menesters ${ }^{6}$. El 27 de març de 1367, Pere Francesc, mestre d'aixa de Mallorca, acordà construir una coca, la Sant Antoni, al lloc dit els Corders, de Ciutat de Mallorca. El contracte especifica que havia de construir la seva barca auxiliar i dos timons, desglossant les despeses de la manera següent:

\footnotetext{
${ }^{3}$ ACM, P 14581, f. 253v.

${ }^{4}$ ACM, P 14583, f. 161r.

${ }^{5}$ ACM, P 14583, f. 226v.

${ }^{6}$ ACM, P 14589, f. 65v-66r.
} 
40 lliures per la feina de mestre d'aixa (manibus de magister axie), 15 lliures de clavaó, 15 lliures de corbam, i 43 lliures i 15 sous per a la fusta de cloenda; s'afegeix que tant la coca com la barca havien d'estar calafatades (clavata de manibus calafatorum), tot i que no s'indica el preu d'aquesta feina, que devia estar inclosa a la del mestre d'aixa ${ }^{7}$. El 13 de desembre de 1367, el mestre d'aixa Bartomeu Pellicer, de Mallorca, convingué amb Joan Sunyer, la construcció d'un lleny, que es diria Sant Jordi i Sant Miquel, a construir al Moll Vell, al barri dels Boters. Les mesures de roda a roda serien de 23 goes $(14,90 \mathrm{~m}), 18$ goes $(11.66 \mathrm{~m})$ de carena, 6,5 pams $(1,40 \mathrm{~m})$ de pla, 12,5 pams a la cinta, 5 pams i mig quart a "lensa dreta" o puntal. A més havia de fer la timonera, els braços i l'esquif, per un preu total de 60 reials a pagar en tres terminis de 20 reials cadascun ${ }^{8}$. Es tracta d'una embarcació tirant a llarga, no la corrent de 3 o 4 entre oberta i llargada total de les embarcacions rodones, sinó de 5,7 (tot i que no arriba al de les galeres, que era de 6 a 8). El 29 de març de 1368, el mallorquí Guillem Blasco, patró de la coca Sant Antoni, d'una coberta, en construcció a Tortosa, fa parçoner d' 1 1/2 setzena al mercader de Tarragona Bernat Arbocer.

Mentre que a Barcelona, el 10 de juliol de 1417, Pere Saragossa fa construir la nau Sant Salvador i Santa Maria, de dues cobertes i un timó, de la qual en seria patró Pere Salvador, que es comprometia a pagar mitja setzena. Poc després aquest va morir havent pagat només 29 lliures, reclamant Pere Saragossa a la vídua el que faltava per pagar: 142 lliures 17 sous 6 diners (el preu total de la nau era de 5.500 lliures $)^{9}$. El 4 de juny de 1418 Tomàs Casell i Francesc Ferrer, fill de Pere, mestre d'aixa, es reconeixen propietaris i patrons indivisos de la nau Sant Jeroni, en construcció a Barcelona i que valia 2.200 lliures ${ }^{10}$.

El contracte de construcció implica l'inici de la fase de concepció, en la qual es defineixen les característiques principals del vaixell que s'ha de construir. Es tracta de la feina més mental que no pas manual, de concebre i donar forma al vaixell, al buc i als seus elements. La gestació comença en el moment que es planta l'estepa i comença el procés de construcció, ara sí, física del vaixell.

\footnotetext{
${ }^{7}$ ACM, P 14636, f. 24v.

${ }^{8}$ ACM, P 14636, f. 155v.

${ }^{9}$ Carrère 1977-1978, vol. I, p. 211, nota 92.

${ }^{10}$ Ibidem, p. 217, nota 120.
} 


\subsection{L'escar}

Es tracta de la primera evidència física de la existència del que serà l'embarcació, quan el mestre d'aixa prepara l'escar, neteja i aplana l'espai on es construirà l'embarcació i posa les peces de fusta que formaran la base de la construcció, el que es coneix com a estepa. Aquesta feina marca l'inici del procés. Un cop posada l'estepa, la primera peça del buc del vaixell que es posa damunt és la carena.

La importància d'aquest acte es pot celebrar amb un ritual, amb l'assistència dels promotors del vaixell i el mestre d'aixa, que pot consistir en el fet simbòlic de clavar un clau a l'estepa o a la carena, de donar un nom propi al vaixell o fer un àpat per a celebrar l'inici de la seva construcción ${ }^{11}$. Hem documentat aquesta celebració en la construcció de galeres a la drassana de Barcelona els anys 1421 i 1423 i en la construcció d'una nau per al rei Alfons el Magnànim a Sant Feliu de Guíxols l'any 1446.

En el primer cas, que es data del 5 d'octubre de 1421, la reina Maria fou present en ficar les stepes a deu galees dins la Darassana reyal e a VIII naus en la platge de Barchinona, atés que el rei era a Nàpols ${ }^{12}$. El segon, es data del 21 de desembre de 1423 el rei Alfons el Magnànim i els consellers de la ciutat de Barcelona es desplacen a les drassanes per a "inaugurar" l'inici de la construcció de dotze galeres:

En lo qual se conté com lo senyor rey y los consellers posaren stepes a XII galeres y con ne beneyren dues." / "Divendres, a XXI de dezembre, any MCCCCXXIII, lo molt alt senyor rey n'Alfonso e los honorables en Phelip de Ferrera, Galceran Carbó, Bernat Serra, Guillem de Soler e Baltasar de Gualbes, consellers l'any present de la ciutat de Barchinona posaren e ficaren dins la Darasana de la mar stepes per XII galeres, ço es, lo senyor rey per sis galeres e los dits honorables consellers per altres VI, però no fou procehit a persequció e perfectió de les dites galeres, sinó de dues de aquelles, les quals los dits honorables consellers ficaren les estepes, la una de les quals es appellada Santa Maria e l'altra Santa Creu, de la hobra de les quals foren administradors assignats per los dits honorables consellers los honrats en Francesc Çatria e Pere de Muntrós, menor de dies, mercaders, ciutadans de la dita ciutat. E fo lo mestre major d'aixa de la dita galera appellada Santa Maria n'Arnau Romeu, e lo mestre calafat de aquella mateixa galera en Bernat Muy; e de la dita altra galera foren lo mestre major de axa en Bernat Loberes, e lo mestre calafat en

\footnotetext{
${ }^{11}$ Veure rituals de possessió de béns immobles en medi terrestre, Puñal 2002, pp. 113-148; Checa, Molina 1997.

${ }^{12}$ Sans 1994, vol. I, p. 38.
} 
Pere Massanet. Item, sobre los dits mestres de axa fou en Pere Blanch $^{13}$.

Tal com diu el document, es posaren dotze estepes, per a la construcció de dotze galeres ( sis pel rei Alfons $\mathrm{V}$ i sis per la ciutat de Barcelona, en aquest cas representada pels consellers Felip de Ferrera, Galceran Carbó, Bernat Serra, Guillem de Soler i Baltasar de Gualbes), tot i la importància, magnificència i pompositat de la cerimònia, al final només se n'acabaren construïnt dues, sembla que per part de la Ciutat.

Els consellers nomenaren administradors de l'obra a dos mercaders ciutadans de Barcelona, Francesc Satria i Pere de Muntrós menor de dies. Tota l'obra quedà sota la coordinació del mestre major d'aixa Pere Blanch, mentre que la direcció tècnica de cada galera anà a càrrec del mestre d'aixa major Arnau Romeu i el mestre major calafat Bernat Muy (o Muner) per a la galera Santa Maria, mentre que la segona galera, la Santa Creu, tenia com mestre major d'aixa a Bernat Lloberes i com mestre major calafat a Pere Massanet.

En el cas de la construcció de la nau grossa Sant Miquel Arcàngel dues dècades després a Sant Feliu de Guíxols també es destaca l'inici de l'obra, amb la celebració del "vi de l'escar". El 8 d'agost de 1446 els mestres d'aixa començaren a treballar a l'escar, deixant tot l'espai de la platja reservat a la seva construcció ben net i ordenat. Ho celebraren, tal com diu el document, bevent "per bon costum" vi blanc, atès que el vi habitual que es consumia a diari era vi negre -“vi vermell"-, només es consumia vi blanc en dates assenyalades. Hem de tenir en compte que la seva construcció fou una de les més importants dutes a terme a la costa catalana durant la Baixa Edat Mitjana, no només era una nau del rei, sinó una de les més grans mai construïdes a la costa catalana, una nau grossa de més de $45 \mathrm{~m}$ de llargada de roda a roda (més de 800 tones de port). La seva construcció durà tres anys, gairebé sense interrupció, fins a la seva varada a finals de l'any $1448^{14}$.

\footnotetext{
${ }^{13}$ Duran, Sanabre 1930, vol. I, doc. 2, pp. 9-10.

${ }^{14}$ ACA, RP, MR 2334. Llibre d'estar de la construcció de la nau reial Sant Miquel Arcàngel a Sant Feliu de Guíxols, per Joan Desperer, escrivà de la nau (anys 1446-1449), f. 272r. En d'altres contexts, com a Gènova, el termini de construcció d'una nau era bastant semblant (Gatti 2008, p. 75): "le navi/galeoni dell'ultimo Cinquecento che portano almeno 6-700 tonnellate metriche, informazioni indirette ci permettono di indicare in circa due anni il tempo complessivo richiesto da una costruzione, comprendendovi però anche un periodo necesario per operazioni di finanziamento e di approvvigionamento di materiali". Totes les construccions de naus lígurs i ragusees es tracten de naus més petites, la més gran de totes és la nau genovesa Santa Maria in Betelen, construïda l'any 1599, de dues cobertes i $31,22 \mathrm{~m}$ de llargada total i 12.000 cantari de port, unes 570 tones (Gatti 1975a, pp. 34-35 i 72; Gatti 1975b, pp. 73-96). Arqueològicament es conserva una nau genovesa d'un port i dimensions semblants a la nau grossa Sant Miquel Arcàngel, es tracta del derelicte Villefranche I o "nave grossa" Lomellina, de dues cobertes, $42 \mathrm{~m}$ de llargada de roda a roda i 800 tones de port, que s'enfonsà a la badia
} 


\subsection{Posar la carena, rodes i quaderna mestra}

Si la primera fase de concepció queda simbolitzada pel gàlib, la segona, més física i visible, queda representada per l'aixa. Els gàlibs permetran al mestre d'aixa traçar la forma de les rodes i la quaderna mestra sobre les peces de fusta, l'aixa permetrà convertir la peça de fusta en les formes adients de cada element de l'estructura del buc.

A sobre de l'estepa es posa la peça més llarga i recta, la carena, formada per una o més peces unides entre sí. Posteriorment s'hi afegeixen les rodes de proa i de popa, aguantant-les amb puntals, tot definint la secció longitudinal principal, i posteriorment s'asseia la quaderna mestra sobre la carena, definint-se la secció transversal principal.

En el cas de la nau grossa de Sant Feliu de Guíxols, no consta la data en la qual es col-locà la carena, si bé podia ser el mateix dia del vi de l'escar -el 8 d'agost de 1446- o l'endemà. Però la feina avançà ràpidament, si tenim en compte que el 13 d'agost s'aixeca la roda de proa ${ }^{15}$ i el 23 d'agost la quaderna mestra (el primer madir fornit $)^{16}$. En la col-locació de les dues rodes i de la quaderna mestra es necessità mà d'obra per a poder manipular aquestes grans peces, per la qual cosa es comprà fruita per tots aquests treballadors. En alguns casos, es podia celebrar un dinar a l'acabar d'enramar tot el buc, que vindria a dir que ja es visualitzava la forma que tindria l'embarcació, encara que no s'hagués folrat encara.

\subsection{El romball}

Es tracta d'una etapa important dins del procés de construcció, és el moment en que es visualitza la forma acabada del buc del vaixell, des de la carena a l'orla i folrada, sovint anomenant el buc en aquesta fase com a "buc blanc". És el moment en el qual els mestres d'aixa prenen una pausa, cedeixen el buc als calafats, els quals prendran el control de l'obra mentre la impermea-

de Vilafranca de Niça l'any 1516 (Guérout 1989). Capmany (1961-1963, vol. I, p. 59) esmenta que el rei Alfons V l'any 1450 posseïa una nau de 4.000 bótes (unes 725 tones), que es podria tractar de la nau Sant Miquel Arcàngel.

${ }^{15}$ ACA, RP, MR 2334, f. 272v. Es comprà "fruita per la companya que ab lo nom de Déu arborà les rodes de proha".

${ }^{16}$ ACA, RP, MR 2334, ff. 274r-300r. El 23 d'agost també es comprà "fruita per donar a beure als qui aydaran arborar lo primer madir fornit". El mes d'agost de 1446 consten pagaments fets per haver traginat per l'escar "IIII peces ha tirades per roda de proha e el gaó de popa", també d'altres moviments de llenyam per a membres i corbam. El 23 de setembre, dia de Sant Miquel, també es consumí vi blanc. 
bilitzen, amb el fil d'estopa i la pega, que el transformaran en un "buc negre". Per aquest motiu els mestres d'aixa celebraven la festa del romball, paraula que fa referència a la peça de fusta que tapa l'últim forat que queda entre les taules del folre ${ }^{17}$.

En la construcció de la nau reial Sant Miquel Arcàngel a Sant Feliu de Guíxols es celebrà la festa del romball el diumenge 9 de juny de $1448^{18}$. Aquesta festa la van celebrar els mestres d'aixa, amb els fadrins i altres tècnics, i hi van consumir diferents tipus de carn, com fetge i melsa de vedell, a més de 49 lliures de carn de vedell, espècies com la canyella, 2 bótes collereses de vi vermell i una bóta colleresa de vi blanc, i de postres fruita. No era habitual el consum de carn de vedell, ni el vi blanc ni la canyella, només en dies assenyalats ${ }^{19}$.

Anys abans, a finals de juny de l'any 1431, començaren les tasques de reparació, modificació i calafatejat d'una galera pertanyent al rei -de la qual el document no n'esmenta el nom- sota la direcció del mestre d'aixa major Bernat de Llobera. El 28 de juny es llogaren 16 homes per a preparar el terreny, netejar-lo i començar a portar peces de fusta, a més un parell d'homes amb un parell de mules passaren durant dos dies la tragella per a esplanar l'es$\operatorname{car}^{20}$. D'altra banda, vint-i-dos calafats començaren a treballar la setmana del 4 de juliol, sota la direcció del mestre calafat major, a més dels seus fadrins. Molts calafats vingueren de Tortosa, essent aquests en bona part musulmans (Abraffim Umeyma, Alí Umeyma, Alí Aytangi, Caydo Uneyma, Alí Çaragon). Les feines de calafat comportaren una despesa de material acostumat, com pans de pega de Castelló (en total 36 quintars, 6 roves, 168 lliures), odres de quitrà (9 quintars, 1 rova, 96 lliures), estopa, pells per fer llanades, llibants d'espart vells per fer barbers, oli, tronyelles, candeles de sèu per a poder treballar sota coberta, etc. La setmana del 25 d'agost el nombre de mestres d'aixa baixà a 18 i el de calafats fou de 22, dels quals 7 eren de Tortosa i d'aquests 4 eren moriscs. D'aquesta etapa de cessió del buc per part dels mestres d'aixa als calafats cal destacar-ne dos fets curiosos. El primer és que el 29 d'agost, festa de Sant Joan Degollat, els mestres d'aixa no treballaren, per ser dia fes-

${ }^{17}$ Garcia, Coll 1994, p. 60.

${ }^{18}$ ACA, RP, MR 2334: "feren le feste del ronbay els mestres segons és usança".

${ }^{19}$ ACA, RP, MR 2334, ff. 268r-300r. En el menú diari consta carn, sense especificar el tipus, per als mestres, mentre la companya menja fetge o freixura. Excepte els dies que no es pot menjar carn, com els diverndres o la Quaresma, en què consta la compra de diferent tipus de peix (sardines, merluces, arengades, congre, tonyina), sobretot salada. Hi han alguns festius en que es menja diferent respecte a la dieta de rutina, per Nadal i Sant Esteve mengen porc, cabrit, un parell de gallines, conills, un anyell, ous, un parell de perdius, a més de les postres típiques, com mel, neules i torrons; semblant al que es menja l'1 de gener, o bé per Carnestoltes o bé quan s'acaba la Quaresma se celebra menjant porcell i anyells, vi blanc i confits "per col-lació".

${ }^{20}$ ACA, RP, MR 2332, especialment f. 80v. 
tiu d'aquest ofici, mentre que els calafats sí que feinejaren; i el segon, que els mestres d'aixa no cobraven, i que per aquest motiu hi hagué un intent de vaga, decidint no posar l'última peça del folre, el romball, fins que els fos pagat el que els devien:

Ítem, acostumen los mestres d'axa que quant han acabade I galea lexen per cloure quant a la popa I troç de taula que apellen rombay, e aquell no volen cloure tro a tant que l'abeurage a tots en general los és pagat per gràcia, per tant lo senyor rey manà al damunt dit en Johan Çafont que per aquell sguard los donàs V s.

El text deixa molt clara la importància d'aquesta fase del procés de construcció, culminada per la figura del romball, petit tros de taula que es posava a la popa, quedant així completament folrat el buc.

\subsection{La benedicció}

La religió, omnipresent a la vida quotidiana a l'edat mitjana, també es troba present en tot el procés de construcció i en la vida del vaixell. Hem vist com els treballadors durant la seva construcció respecten les festivitats religioses, no treballant aquests dies, en alguns dies concrets hi ha algun sector dels mestres que treballen i d'altres no per ser festiu d'un gremi en particular, els divendres i altres dies i períodes concrets de l'any no mengen carn per prescripció religiosa, etc. És evident doncs que si el bateig d'un nadó és una cerimònia molt important en la vida d'una persona, també ho serà la benedicció i bateig d'un vaixell.

Un nadó batejat deixa de ser un albat i passa a formar part de la comunitat de cristians, una persona amb nom i cognoms. Una embarcació que sigui beneïda i batejada no només rebrà la protecció divina i tindrà un nom del santoral ${ }^{21}$, sinó que, un cop varada, serà per primera vegada un vaixell, i no tan sols una estructura de fusta.

Per poder ser beneïda una embarcació calia primer demanar llicència al bisbe pel motiu de celebrar-se un acte litúrgic com era la benedicció en un lloc que no era un temple o no havia estat consagrat. El segon és que el capellà s'havia de traslladar fins a la platja per a oficiar la missa i celebrar la benedicció a dalt del vaixell si era gran o al seu costat si era una embarcació menor.

${ }^{21}$ Coll 1988, pp. 35-40; Bresc, Bresc 1979, pp. 161-178; Bresc 1981, pp. 427-443; Balbi 1966, pp. 65-86. 
És molt probable que la complexitat del procés i el cost econòmic de tot plegat, fes que només les embarcacions més grans, com les naus i les galeres, es beneïssin. En relació al període medieval tenim documentades benediccions d'embarcacions a Barcelona, Sant Feliu de Guíxols, Palamós i Blanes, però en tots els casos es tracten d'embarcacions de port gran i mitjà, mai en cap cas ens apareix una embarcació menor, com una barca de ribera o un llaüt de pescador ${ }^{22}$.

Coneixem algunes llicències concedides pel bisbat de Girona, com la que es concedí per celebrar missa a la varada d'una galera a Blanes el 9 de desembre de $1391^{23}$ i la de beneir la nau de Pere Saragossa, acabada de construir a Blanes, el 23 de maig de $1414^{24}$. Tenim constància que l'any 1424 es demanà llicència per a poder beneir la nau de Gracià Amat, de Barcelona, acabada de construir a Sant Feliu de Guíxols. En aquest darrer cas la resposta es donada per part del vicari general Joan de Palomar als clergues de l'església del monestir de Sant Feliu de Guíxols, a fi que la dita nau i els que hi naveguessin junt amb les seves mercaderies poguessin fer camí arreu feliçment i pròspera. La llicència episcopal subratlla que es podia erigir dins de la mateixa nau, en un lloc estable i ferm, un altar portàtil, i, una vegada erigit i posant-hi una ara consagrada i decorant-lo decentment al damunt amb estovalles i altres ornaments necessaris, perquè hi poguessin celebrar la missa i les oracions i benediccions acostumades, excloent de l'assistència els excomunicats i sotmesos a pena d'entredit ${ }^{25}$.

\footnotetext{
${ }^{22}$ En el cas de l'estudi de les llicències del bisbe de Girona per a beneir embarcacions, publicat per Marquès 1992, no hi apareix cap de la costa del comtat d'Empúries. Hi podrien haver dues raons, per una banda no es construïen vaixells de gran port, o bé no es demanaven llicències al bisbe, per la voluntat comtal de disposar d'un bisbe propi, i que potser les benediccions les fessin directament els abats dels monestirs de Santa Maria de Roses i Sant Pere de Roda als ports de les seves jurisdiccions.

${ }^{23}$ ADG, U-080, 00268, f. 74r.

${ }^{24}$ ADG, U-114, 11237, f. 27r.

${ }^{25}$ Marquès 1992, p. 10, ap. 1.1424 abril 10. Minuta d'autorització per a beneir la nau de Gracià Amat, de Barcelona, acabada de construir a Sant Feliu de Guíxols. ADG, U-124, f 104. "Iohannes de Palomar etc. vicarius etc. dilectis nostris in Christo clericis /ecclesie monasterii Sancti Felicis Guixellensis, diocesis Gerundensis, / salutem in Domino. Cum venerabilis Gracianus Amat mercator civis / Barchinone quandam navim propriam noviter in dicto loco Sancti Felicis / fabricatam cupiat marinis fluctibus sociare, idcirco admissa supplicatione / humili super huiusmodi nobis facta ut dicta navis et navigantes in eadem / cum suis mercimoniis ubique prospere et feliciter dirigantur, quatenus /intus eandem navim, ipsa in loco stabili atque firmo permanente, altare /portatile erigere seu erigi facere atque in eo sic erecto ara cum consecrata / superposita ipsoque corporalibus, pannis, palleis atque aliis ornamentis / ad hoc necessariis decenter ornato, excommunicatis tamen et interdictis / exclusis, missam cum orationibus et benedictionibus in similibus assuetis / celebrare libere et licite valeatis, dicti domini episcopi auctoritate / concedimus per presentes. Datum Gerunde X die aprilis anno a nativitate / Domini M CCCC XX IIII."
} 
La litúrgia i tot l'acte devia tenir un origen molt antic, barrejant fe i pietat popular per l'atorgament d'una major seguretat i protecció sobrenatural a un element terrestre que havia de surar, ser estable, maniobrable, ràpid, lluitar contra el mar, el vent, la pluja, les tempestes, els enemics, etc.

El relat de l'acte de benedicció també s'esmenta al Llibre de algunes coses assenyalades, on explica que el diumenge 13 d'agost de 1424 es van beneir a Barcelona dues galeres amb la presència del rei, dels consellers i altres ciutadans. El bisbe de Girona va celebrar una missa i les va beneir d'acord amb l'ofici de la benedicció:

E diumenje a XIII del mes de Agost any MCCCCXXIIII acabades les dites dues galeres foren benehides e a la benedictió de aquelles fou present lo dit senyor Rey. E los honorables consellers e mols honorables ciutadans fou hi encara present lo reverent Bisbe de Girona lo qual dix la missa e feu lo offici deia benedictió de les dites galeres. E en Pere Parri, mariner, dix la bona paraula ${ }^{26}$.

No es tracta de l'única referència coneguda per a Barcelona. En tenim d'altres anteriors, per exemple de l'any 1358, del 25 de juliol, en que un sacerdot, acompanyat de sis clergues més, va procedir a la solemne benedicció de dues galeres. A més d'una companyia de cinc joglars, entre els quals destacava el trompeta Pons Cabrera, van ser presents a l'acte per tal de donar-li un aire més festiu ${ }^{27}$. El capellà, abat o bisbe que oficiava la missa batejava amb el nom de la Mare de Déu o algun sant o santa, o amb una doble o fins i tot triple invocació, però mai amb el nom de Déu. I a l'acabar la benedicció de les dues galeres del 1424 en Pere Parri mariner dix la bona paraula ${ }^{28}$, desitjant la millor sort del món per a la galera i la seva tripulació. Capmany ${ }^{29}$ ho interpreta dient que el mariner cridà a lluitar contra turcs i francesos. Una crida discutible donat que la presència de turcs a la Mediterrània encara no s'havia fet ben present.

El ritual sol seguir sempre unes pautes, que poden ser més o menys riques, per la presència de més o menys capellans, músics, personalitats i públic. A l'abadia de Jumièges (Normandia) es conserva un missal del segle XII amb el ritual de la Benedictio novae navis, en que el capellà amb la comitiva arribats en processó al vaixell, beneïa a proa, recitant l'Evangeli de Sant Joan,

\footnotetext{
${ }^{26}$ Duran, Sanabre 1930-1947, vol. I, doc. 2, pp. 9-10. 1424, 13 agost.

${ }^{27}$ Estrada 2004, pp. 113-114. ACA, RP, MR, 2291, f. 204r.

${ }^{28}$ Ramon Muntaner també en fa esment: "E digueren la nona paraula e anaren-se'n a la bona hora", com a salutació dels mariners o bé com a pregària. Muntaner, Crònica, a cura de Marina Gustà, cap. 219.

${ }^{29}$ Capmany 1787 , ap. 25-26.
} 
després a la popa, recitant el temporal calmat per Jesús, i al peu de l'arbre, entonant l'Spiritus Domini i l'Evangeli de la vigília de Pentecostès, s'acabava el cerimonial amb vi: Postea debent habere bon vinum a cellario. A inicis del segle XIV el Pontifical de Guillaume Durand inclou una oració tendent a allunyar la mala fortuna i concloure feliçment la travessa ${ }^{30}$.

Com hem vist en una de les referències, la benedicció de diverses embarcacions a Sant Feliu de Guíxols i Palamós seguia les pràctiques acostumades i segons el que prescrivia el bisbat de Girona. El procediment devia venir donat pel ritual de la Benedictio novae navis ${ }^{31}$.

El capellà, amb tota la comitiva, sortien de l'església en processó fins a la platja, a l'escar, on estava construïda la embarcació que havia de ser beneïda. En primer lloc el capellà pujava dalt del vaixell, se situava a la popa $i$ recitava el Psalm 106, es pregava, es llegia un passatge de l'Evangeli de Marc: La tempesta calmada (Mc 4, 35-42) ${ }^{32}$, en que Jesús s'embarca en la barca de pescadors per a que el duguin a l'altra costat del mar de Tiberíades. Mentre s'adorm a la popa es desferma un temporal, quan es desperta, fa calmar el mar i el vent. El ritual continuava amb una pregària i es recitava el Psalm Afferte Domino (apèndix 4) mentre anava aspergint aigua beneïda per la popa.

Seguidament el capellà es desplaçava cap al mig del vaixell. Aquí llegia un passatge de l'Evangeli de Mateu: Jesús camina sobre les aigües (Mt 14, 22-32), en que els pescadors són dalt de la barca a certa distància de la riba, arriba Jesús i en comptes d'acostar-s'hi nedant, hi va caminant sobre l'aigua. Es pregava i es recitava el Psalm 76 mentre beneïa amb aigua la part central del vaixell.

En tercer lloc es desplaçava cap a la proa. Aquí es llegia de nou un passatge del Nou Testament, de Lluc: La pesca miraculosa (Lc 5,1-11) en que Jesús fa la crida als primers deixebles, els quals tornaven de pescar en dues barques sense cap peix, manant-los que tornessin a calar la xarxa. Ho tornen a fer, produïnt-se el miracle, lleven l'art ple de peix. La cerimònia continuava amb la pregària i es recitava el Psalm 45 mentre s'aspergia amb aigua beneïda tota la proa.

Finalment, es tornava de nou al mig del vaixell, es llegia novament un passatge del Nou Testament, de Joan: Jesús camina sobre les aigües (Jn 6, 16-21). Es pregava, es cantava i es recitava el Kyrie eleison, el Pare nostre, l'Ave Maria, el Crec en Déu, mentre s'anava aspergint amb aigua beneïda. En acabat, es tornava a pregar, el Salve Regina i l'oració Concede nos famulos tuos.

\footnotetext{
${ }^{30}$ Mollat 1979, p. 194.

${ }^{31}$ Martínez 1840, pp. 431-441.

${ }^{32}$ La Bíblia 2008.
} 
De fet, el dia de la benedicció de l'embarcació tenen lloc tres cerimònies. La primera és pública i religiosa, on hi participen les autoritats polítiques i eclesiàstiques, els propietaris del vaixell, els constructors i tota una massa d'espectadors de la vila i port on s'ha construït. A l'acabar la benedicció religiosa es produeix una segona cerimònia, també pública, però de caràcter laic, l'intercanvi dels anaps per l'aixa i el marc. La tercera part és també festiva, però en aquest cas gastronòmica, laica i més íntima, és la que duen a terme els mestres d'aixa i altres operaris, amb la celebració d'un dinar.

Atès el nombre limitat de documents medievals que hem pogut localitzar, hem volgut conèixer la existència i pervivència d'aquests costums practicats pels mestres d'aixa en l'Era Moderna. Avançant en el temps, a inicis del segle XVIII a Sant Feliu de Guíxols, documentem la construcció i baptisme de tres navilis del rei Felip V. L'abat Isidor Couvarem demanà llicència al bisbe Miquel Joan de Taverner que la concedí el 17 de maig de 1717, l'endemà mateix l'abat va beneir el navili de tres cobertes i 80 canons, el Reial Sant Felip ${ }^{33}$, essent-ne padrí Josep Vicià, coronel del regiment d'Infanteria de Cantàbria i comandant de la plaça de Sant Feliu de Guíxols:

Al divuyt del any mil set cents y disset fou benehit lo vaxell de guerra construit en la plaja de la present vila ab solemne benedictio y demes ceremonia que acostuma Ite Mage la Iglesia par los Srs Abat Sr Isidoro de Couvarem ab assistencia de la venerable comunitat de monjos i preveres, assistí com padrí Mn Joseph Vicarià coronel del Regiment de Infanteria dit de Cantàbria, comandant plasa de la present vila, lo nom en invocació del Sant, se posà per patró a juhitar de dit vaixell fou St Felip apòstol per honor y memoria de Nre Rey i Sr Don Felip Quint C y S Déu y de M. La benedicció se feu en la forma seguent. Isqué de la Iglesia lo Molt $\mathrm{Sr}$ Abbat revestit de Casa ab la Insignia abacial de mitra y baculo, assistí de ministre Ramon revestits en prosesso solemne ab assistencia de la venerable comunitat de monjos y preveres, precehint la Bandera y Gamferons de la Confraria y arrivant al vaxell, se feu ab solemnitat la benediccio del vaxell ab las ceremonias acostuma Ntra Mare la Iglesia. Despres se canta sobre la popa missa solemne ab musica, la qual celebra lo Molt Illtre Sr Abbat de ministre, assant lo Sr Abbat de mitra y baculo encara ana celebrà missa Pontifical, si no merament missa abacial, acabada la missa se feu la Benediccio de la bandera y armas del vaxell ab la qual benedicció se terminà, la funció dins lo vaxell, anantse a la Iglesia lo Sr Abbat assistit dels ministres y venerable comunitat de monjos y preveres, que avia exit de la Iglesia per anar a benehir lo vaxell ${ }^{34}$.

${ }^{33}$ Julià 1985, p. 160.

${ }^{34}$ Fuente, Pujol 2010, pp. 71-72, notes 119-120; ADG, Lletres (1586-1819), U-274, f. 105; ADG, Parroquial de Sant Feliu de Guíxols, Baptismes 328, B6 (1692-1726), f. 241r-v. 
Els altres dos navilis, de dues cobertes i 60 canons, foren acabats i beneïts els anys 1718 i 1719. El 16 d'agost de 1718 el bisbe de Girona, Josep de Taverner, concedí la llicència per a la benedicció del primer, la qual es realitzà el 24 d'agost, pel prior Plàcid Julià i en fou padrí el governador de Girona, el marquès Don Tiberio Caraffa. El navili fou batejat amb el nom de Sant Bartomeu Apòstol, àlies Cambi ${ }^{35}$. El 22 de maig de 1719 el bisbe Josep de Taverner concedí llicència per a beneir el tercer vaixell, celebrant-se la cerimònia el 2 de juny per part del prior Plàcid Julià, batejant-se amb el nom de Nostra Senyora de Montserrat, si bé li quedà el nom de lo Cathalà, i en va ser el padrí Francisco Fordés, major de la Reial Armada i capità del vaixell ${ }^{36}$.

Alfons Garrido ha recollit alguns exemples recents de benedicció de barques de l'entorn de Palamós a partir del buidatge dels registres parroquials de baptismes, tots ells datats als segles XVII i XVIII -entre els noms del nadons apareixen els noms de les embarcacions-. La primera data del 24 d'octubre de 1781, en que el patró pescador Francesc Llopis va fer beneir per la comunitat de preveres la seva nova barca de pesca a l'Arenal, davant la casa del pescador Feliu Sureda, on acabava de ser construïda ${ }^{37}$. A l'any següent, el 1782, ara en una embarcació mercant es celebra una festa: En lo mateix Pinco lo senyor capità donà refresch ahont foren convidats molts senyors $i$ senyoras y també la reverent comunitat de preveres. I al 1783 es beneïa una nova nau $y$ després de dita benedicció he celebrat en lo altar dels Dolors una missa resada a la intenció del Patró, me ha estat convidat a prendre xocolata en sa $\operatorname{casa}^{38}$. Finalment, Garrido recull també una notícia del segle anterior, del 17 de gener de 1668:

$\mathrm{Ab}$ interventió dels preveres de la Reverent Comunitat de dita Iglesia Parrochial de Palamós, anant processionalment ab creu alsada, ab las capas publials i majors de dita Iglesia, y capiscol també ab ses capes publials y Vera Creu, ab acompanyament de musichs de cant y totas las demés solemnitats que acostuma fer-se professó és estada benehida en lo port de la present vila de Palamós una barcha grossa del Senyor Jaume Joan Botet, lo corrent any Jurat de dita vila de Palamós y patrocinada per dit Senyor Jaume Joan Botet y lo feu la dita benedicció en la forma acostumada y segons lo ritu y serimonia fet en semblants benediccions conforme aporta lo ordinari el dit Bisbat de Gerona. Foren padrins lo Sr. Joan Ferriol y Cortada, negociant de Begur, y la Sra.

\footnotetext{
${ }^{35}$ Fuente, Pujol 2010, p. 104, nota 175; ADG, Lletres (1586-1819), U-274, f. 156v; ADG, Parroquial de Sant Feliu de Guíxols, Baptismes 328, B6 (1692-1726), f. 255r.

${ }^{36}$ Fuente, Pujol 2010, p. 113-114, nota 197; ADG, Lletres (1586-1819), U-274, f. 185; ADG, Parroquial de Sant Feliu de Guíxols, Baptismes 328, B6 (1692-1726), f. 263v.

${ }^{37}$ Garrido 2006, p. 79, nota 141; APP, B7, s.f. 1781, octubre, 24.

${ }^{38}$ Garrido 2006, p. 79, nota 143 i 144; APP, B7, s.f. 1782, maig, 21. 1783, juny, 20.
} 
Eulalia Canera muller de Miquel Caner, mercader de dita vila de Palamos a la qual barca per dits senyors padrins fonch possat nom Nostra Senyora de Gratia, Sant Antoni de Pàdua, Sant Nicholau y Santa Bàrbara ${ }^{39}$.

I finalment una pràctica contemporània i curiosa és la que esmenta Joan Amades per al cas de Barcelona a l'inici del segle XX. En un acte celebrat a la costa barcelonina, el capellà baixava a la platja per oficiar el bateig, tirava aigua al fons de la barca que després era recollida i llançada al mar, el bastiment era posat l'aigua a vista dels convidats i s'organitzava finalment un àpat festiu ${ }^{40}$.

\subsubsection{L'intercanvi de regals: anaps, aixes i marcs}

Els anaps són les copes d'argent, i sovint daurades, que l'armador oferia als mestres majors el dia de la benedicció de la galera o de la nau, i a canvi els mestres majors d'aixa i calafat lliuraven respectivament les seves eines, l'aixa i el marc (el petit martell de calafatar), com a símbol de la feina acabada. Sembla que era un costum practicat tant en la construcció naval per al rei com per al Consell de la ciutat de Barcelona.

Tornant a reprendre la construcció de galeres a la drassana de Barcelona l'any 1424 , veiem clarament com acabada la benedicció es duia a terme l'intercanvi de regals entre els armadors i els mestres d'aixa i calafat:

En lo qual se conté com lo senyor rey y los consellers posaren stepes a XII galeres y con ne beneyren dues. / (...) E diumenge, a XIII del mes de agost, any MCCCCXXIIII, acabades les dites dues galeres foren benehides. E a ala benedicció de aquelles fou present lo senyor rey e los honorables consellers e molts honorables ciutadans; fou-hi encara present lo reverent bisbe de Girona, lo qual dix la missa, e feu lo offici de la benedictió de les galeres. E en Pere Parri, mariner, dix la bona paraula. E fet lo offici de la dita benedictió, segons forma acostumada, lo honorable en Galceran Carbó, conseller segon e n'Arnau Romeu, mestre major d'aixa e en Bernat Muner, mestre major calafat, benehiren la una galera appellada Santa Maria. E lo dit honorable en Galceran Carbó dóna una copa daurada al dit Arnau Romeu, lo qual donà al dit honorable en Galceran Carbó una axa. E altra copa donà al dit Bernat Muner, mestre calafat lo qual donà al dit honorable en Galceran Carbó un march. E per lo honorable en Bernat Serra foren donades sengles copes daurades als dits mestres de axa e

\footnotetext{
${ }^{39}$ Garrido 2006, pp.78-79, nota 140; APP, B3, s.f. 1668, agost, 11.

${ }^{40}$ Amades 1950, p. 823.
} 
de calafat, e lo mestre de axa donali una axa, e lo calafat donali un march. Item, fou mestre major e sobre tots los altres en Pere Blanch, mestre d'axa, al qual foren fetes certes aventatjes a ell promeses y entre els altres li foren dades per los dits honoables dues copes semblans de les susdites. E lo dit Pere Blanch doná als dits honorables dues axes, axí que les dites axes foren IIII e los marchs II, los quals ells s'o partiren ${ }^{41}$.

Si la primera part del document data de l'any 1423 i fa referència a la plantada de l'estepa a l'escar per a dotze galeres, la segona part, que data del 12 d'agost de 1424, fa referència a l'acabament de la construcció de dues galeres. Aquestes són beneïdes pel bisbe de Girona 'segons forma acostumada', amb la presència del rei i els consellers de la Ciutat. A l'acabar l'acte religiós el mariner Pere Parri donà la bona paraula. Tot seguit el conseller Galceran Carbó donà una copa daurada al mestre d'aixa Arnau Romeu i al mestre calafat Bernat Muner per la construcció de la galera Santa Maria, a canvi ells donaren una aixa i un marc. El conseller Bernat Serra donà una copa daurada al mestre d'aixa Bernat Lloberes i al mestre calafat Pere Massanet per la construcció de la galera Santa Creu, i aquests a canvi li donaren una aixa i un marc. El director de tota l'obra Pere Blanch donà una aixa a cada conseller i cadascun li donà a canvi una copa daurada. En total foren repartides 6 copes, 4 aixes i 2 marcs.

Una altra referència barcelonina posterior, que data de l'any 1466 , diu el següent: Fou beneyda en la dressana la galea (...) e foren donades dues copes d'argent (...) la una al mestre major d'axa, e altre al mestra calaffat ${ }^{42}$. I també alguns exemples més antics, que remunten al segle XIV. En el llibre de comptes de l'any 1359 s'aprecia l'obsequi, en la construcció de galeres, per a metre-les en la caça e en la copa de la benedicció de la galea reyal ${ }^{43}, \mathrm{i}$ aquesta altra referència: Ítem, liure a $n$ Bernat Riba, mestre d'axa, ciutadà de Barcelona, una tassa d'argent daurada, (...) la qual (...) li liure lo dia que fo beneyda la demunt dita galea ${ }^{44}$.

També se celebrava aquest costum a la drassana reial de Mallorca. El 1314, en un llibre de comptes hi consta la despesa efectuada per la compra d'un anap d'argent que s'havia de lliurar al responsable d'obrar una galera nova $^{45}$ : compra de I anap d'argent que donà a.n Casteló Olmay, que havia feta I galea nova, segurament la galera Santa Àgata que posteriorment seria bruscada i correguda. En un altre llibre de comptes de l'any 1326 es fa constar que:

\footnotetext{
${ }^{41}$ Duran, Sanabre 1930-1947, vol. I, doc. 2, pp. 9-10. 1424, 13 agost.

${ }^{42}$ Carreras, Schwartz 1892, vol. II, p. 470.

${ }^{43}$ Estrada 2004, pp. 113-114. ACB, Extravagants, PR 1359, "Reebudes de Guillem Oliver...", f. 4v.

${ }^{44}$ ACA, RP, MR 2307, f. 35r-v.

${ }^{45}$ Sastre 1994, ap. I, p. 175; ARM, RP 3026, f. 9v-10v.
} 
Item, pagam per gracia e per bendiccio e per valor de II anaps dargent... X libras. (...) Item, pagam en moltes e en diverses partides per les messions que foren fetes al varar de les dites II galeas en lo pan de la benediccio e per la ofrena e per so que donam als clergues e per messions de juglars e per la mession que fo feta en manjar als lavorans e per altres messions fetes per lo dit varar, axi con se conten al llibre manual asumat... XI libras XVI sous ${ }^{46}$.

Al segle XVI encara es mantenia aquest costum. El 1506, en els comptes de l'estol de nou galeres construïdes a Barcelona per Ferran el Catòlic: A cada constructor mayor y maestro calafate, que hicieron las galeras, se regaló una copa de plata sobredorada, según costumbre, de un marco de peso, su valor 188 sueldos barceloneses ${ }^{47}$. És probable que el costum de l'intercanvi de les copes daurades i les eines dels mestres, habitual en les grans construccions i de caràcter institucional s'anés perdent durant l'Era Moderna, amb el declivi produït en les construccions navals d'aquest tipus a Catalunya, pràctica que desapareix definitivament a l'acabar la Guerra de Successió amb la implantació del Decret de Nova Planta l'any 1715.

En d'altres àrees de la Mediterrània es practicava un costum similar. A Gènova, a la fi del segle XVI es feien diversos tipus de regals, com per exemple una bóta de vi, i a la segona meitat del segle XVII i inici del XVIII, els mestres d'aixa rebien, en l'acabar l'obra, una cadena d'or de part de l'armador, amb un preu que se solia situar entre les 300 i les 500 lliures ${ }^{48}$.

\subsubsection{El gran àpat dels mestres}

Acabada la benedicció i bateig de la embarcació i dels intercanvis de presents entre el senyor de la nau i els mestres, tothom es retirava. Els clergues en processó cap al temple d'on havien sortit, el senyor de la nau cap a la seva residència i els mestres cap al lloc on dinarien.

\footnotetext{
${ }^{46}$ Ortega 2015, p. 37, nota 84. ARM, RP 3051, f. 51v-52v.

${ }^{47}$ Capmany 1787, ap. IV, p. 31.

${ }^{48}$ Gatti 1999, pp. 336, 346, 349; Gatti 2004, pp. 67-68: "Le catene o collane d'oro sono i premi che gli vengono elargiri -in due casi della Repubblica, in un terzo da commitenti privatiper la direzione delle sue più importante construzioni finota note: tre grandi navi ármate (nelle fonti indicate anche come galeoni o vascelli) realizzate negli anni Sessanta e Settanta". Nota 39: "Il valore delle catene o collane, con annessa medaglia, ammonta un poco più di 300 lire per la seconda unità, la "N.S. dell'Apparizione e S. Pietro", e a poco meno di 420 per la terza, la "S. Giovanni Battista": in quest'ultimo caso il maestro lamenta di aver ricevuto per la prima costruzione pubblica -la nave Capitana- una catena di valore nettamente superiore e ottiene dalla Repubblica una integrazione di 500 lire" (...) "Una trentina d'anni dopo, per una nave terminata nel 1703, l'ignoto capo maestro riceve in regalo una collana del valore di 900 lire" Lo Basso 2004, pp. 85-125.
} 
Els mestres majors d'aixa i calafat, junt amb la resta de mestres d'aixa i calafats i els seus ajudants, i sovint d'altres treballadors de l'obra, feien un gran dinar per a celebrar el dia de la benedicció de la nau o la galera i la fi de la feina realitzada en terra, donat que l'endemà o molt aviat començaria el procés de la seva varada. La benedicció i el dinar es solia fer en diumenge, així doncs la varada s'iniciaria el dia següent, el dilluns.

En el dinar es menjava i bevia en abundància, amb una presència de consum de carn no habitual, com era la carn de vaca i bou, animals que es mataven expressament per al gran àpat, i per a beure vi negre, a més de vi blanc, que també es bevia en dies especials com aquest.

Elisa Ferreira també comenta que la celebració del dinar el dia de la benedicció o varada de la embarcació era un costum que es practicava a Galícia. En els Costums de Noia, de l'any 1435, consta que Iten ha de auer el mayordomo la meytad de los dineros que dan e ofrecen en los baxeles nuevos e en las naos que fazen en la villa quando los uotan, e que dan a los clerigos que van y a dexier el evangelio ${ }^{49}$. Aquest costum podria tenir una relació amb el que feien també els mestres de cases a Catalunya, que a l'acabar la teulada de la casa en construcció oferien un dinar als seus treballadors. El fet de tenir la teulada acabada significava que l'estructura ja era una casa, encara que s'hagués d'acabar el seu interior, posar portes i finestres, etc; igual que un vaixell, amb el buc folrat i calafatejar ja pot surar, i qui diu surar, diu navegar, encara que faltés acabar l'interior, les superestructures i l'eixàrcia.

Disposem d'una referència documental del dinar de la benedicció o dinar dels mestres celebrat aquest dia. El dia de la benedicció de la nau grossa Sant Miquel Arcàngel a Sant Feliu de Guíxols, el 16 de juny de 1448, els mestres i altres treballadors compartiren un gran àpat. Els dies previs, el 14 i 15, consten al llibre de comptes compres de menjar i beure, no habituals, indicadors que s'acostava un dia especial. El divendres es comprà peix per al nauxer, els mariners, els mestres d'aixa, els ferrers e per la gent nos aydaren a metre a punt per beneyr a dinar e sopar, i el dissabte es compraren vuit bótes collereses de vi vermell, dues bótes collereses "per lo beneyr", vi blanc i fruita "per lo beneyr". S'envià un noi a Girona a buscar la llicència del bisbe per a poder fer la benedicció i es comprà un ciri i candeles de sèu per l'acte, els ferrers fabricaren 200 aguts (o claus) petits per fer els bancs que s'havien de fer servir durant la benedicció de la nau.

Així, una setmana després de la festa del romball, el diumenge 16 de juny es beneeix la nau (beneïm en lo nom de Déu la nau), i es bateja amb el

\footnotetext{
${ }^{49}$ Ferreira 1994, pp. 159-171. Després feien un gran banquet, que sembla que els Reis Catòlics van intentar prohibir, segons la Pragmàtica de 1493.
} 
nom de Sant Miquel Arcàngel. Per a la missa es fabricaren els bancs, es comprà un ciri de tres lliures de pes, una lliura de candeles de cera, i quatre copes daurades comprades a Joan Espano, argenter, que pesaren quatre marcs, per un preu total de 19 lliures i 10 sous $^{50}$.

Acabada la benedicció es féu un gran àpat. A banda del vi que s'havia comprat durant la setmana, es consumí una gran quantitat de carn no present al menú habitual: 43 lliures de bou, a més d'un bou que fou portat d'Aro i escorxat pel carnisser de Sant Feliu, 73 lliures de vedell, 9 lliures de carn d'altre tipus, $\mathrm{i}$ dues freixures i fetges -aquests dos últims eren però un menjar habitual de la companya-. Per a poder menjar i beure Nicolau Madrenchs, mercader de la vila, deixà vaixella d'obra de terra de diferent tipus.

\subsection{La varada}

En tota embarcació, quan el mestre d'aixa creu que ja ha acabat tota la seva feina a l'obra viva i que el calafat ja dona per acabada també la tasca d'impermeabilitzar el buc, entre tots dos consideren que la embarcació ja pot anar a l'aigua.

És evident que sempre hi havia feines encara per fer: acabar l'interior, les cobertes, els castells de proa i de popa, posar, tallar o pintar els elements decoratius, arborar, eixarciar... però tot i que pot restar molta feina encara fins que el vaixell estigui llest per navegar, els dos mestres consideren que el buc a l'aigua ja surarà.

Com que es tracta d'un moment molt important en la vida del vaixell, en què tot el procés dut a terme fins ara era la seva concepció i la gestació, el pas de terra a l'aigua el podríem considerar com el seu naixement, l'inici de la seva vida, de la funció per a la qual ha estat concebut i construït.

Però abans de varar la embarcació, calia preparar el terreny per a conduir-la cap al mar, preparar la superfície de la platja, cavar-la o allisar-la, posar-hi els parats o l'escala de varar, i el més important, abans de moure-la, calia rebre la benedicció divina i s'havia de batejar. Aquesta fase del procés es pot dur a terme el dia de la benedicció, l'endemà o al cap d'una setmana. Tot depenia de la complexitat del procés de varada, a causa del pes i volum de l'embarcació, i també d'altres causes, com l'estat de la mar i de l'escala de varar o camí des de l'escar fins a l'aigua. Es tracta d'una etapa realment important i complicada, la primera vegada que tota l'estructura s'havia de moure,

\footnotetext{
${ }^{50}$ És probable que les copes o anaps es lliuressin als quatre mestres, al mestre major d'aixa, als dos mestres majors calafats i al mestre major de l'arborar.
} 
desplaçant-se per l'escala de varar. No només es un moment dinàmic sinó que es passa d'un medi terrestre cap a l'aquàtic per a la qual va ser construït i on es faria evident si podria complir amb la seva funció.

En el cas de les naus, aquestes destacaven pel seu gran volum i pes, una operació realment complexa i delicada, si la comparem amb altres embarcacions grans com les galeres, que podien arribar a ser gairebé tan llargues, però tenien molt menys puntal i oberta, a més de que eren construïdes amb materials molt més lleugers. La varada d'una nau requeria d'una bona escala de varar, talles i torns de varar a la banda de muntanya per a evitar que la nau prengués velocitat, de barques al mar que lligaven a la nau per a controlar-la i dirigir-la, a més de molts altres caps que eren tirats per una munió d'homes. La gran quantitat de personal que requeria la varada d'una nau feia necessari fer una crida, en el cas de Barcelona per tota la ciutat i en el cas de Sant Feliu de Guíxols anar a buscar gent a altres poblacions pròximes ${ }^{51}$.

Primer calia posar els vasos contra els costats de la nau, lligar i estrènyer amb caps els vasos dels dos costats entre ells. Així s'aconseguia que la nau s'aixequés una mica per sobre de l'estepa, deixés de recolzar sobre aquesta i passés a recolzar-se sobre els vasos ${ }^{52}$. Si es podia es desmuntava l'estepa. Es muntava l'escala de varar des de l'escar fins al mar, i així ja es podia començar a moure la nau asseguda sobre els vasos i aquests lliscant per sobre de l'escala. Un munt de gent estirava els caps per les dues bandes de la nau, mariners, servicials, esclaus i altre tipus de persones vingudes del port i la ciutat, tots plegats, seguint les ordres del mestre d'aixa major, al crit d'“Aioç!"53.

La nau havia d'avençar a poc a poc, sense encallar-se, sense inclinarse, davant del possible risc que bolqués. L'operació s'havia de fer lentament, controladament i amb tota seguretat. Calia prendre totes les mesures, humanes i tècniques, per tal d'assegurar-se l'èxit de la varada. El camí de varada era llis, amb l'escala de varar, i amb la inclinació apropiada cap al mar. El vaixell no podia bolcar de costat perquè estava assegurat per sota amb els vasos, que fixats contra el buc, i lligats entre ells mitjançant caps, permetien lliscar con-

${ }^{51}$ El mes de maig del mateix any 1456, la nau de Nicolau Salvador, dit el Botifarrer, estava llesta per ser varada, però la dificultat per fer-la avall cap a mar va fer que els consellers fessin crida per la ciutat de Barcelona convocant a tota la gent de mar a ajudar a varar-la. Carrère 1977, vol. I, p. 193.

${ }^{52} \mathrm{Al}$ Llibre del Consolat de Mar ens dóna una certa informació sobre aquest procés: "Si a instància de creedors nau o leyn o altre vaxel que de nou serà construhit, abans que sia verat e levat de les stepes, o abans que haja fet alcun viatge serà venut...". Colon, Garcia 1981-1987, vol. I, cap. 32.

53 "Aioç!" era el crit que es feia servir entre la gent de mar al fer grans esforços com al varar i treure una embarcació, llevar àncores o l'antena, o bé en la voga de les galeres. Jaume I, Crónica o Llibre dels Feits, a cura de Ferran Soldevilla, cap. 161: "Cridam ayoç, axí com fa hom al varar d'una nau". 
juntament a la quilla -i per tant tot el buc-i els vasos sobre l'escala de varar, tots ells ben enseuats. La velocitat es controlava per una banda pels homes que empenyien cap al mar i per l'argue i la talla de varar que evitaven que agafés massa velocitat. La direcció també era controlada, tant per l'argue i la talla de varar des de terra, com per una embarcació amb un cap des del mar ${ }^{54}$.

Segons sembla les naus es varaven de popa, així ho indica la iconografia coneguda per a la fi del segle XV i l'inici del XVI a Itàlia ${ }^{55}$ i a Portugal. No serà fins al segle XVII que tenim les primeres varades de naus per proa.

La dificultat i la lentitud en la varada d'una nau queda palesa l'any 1456 a Barcelona, en que la nau de Jaume Pertegàs hi va estar un total de 42 dies:

Dimarts, 27 d'abril de 1456, en Jacme Pertegàs, començà a verar la sua nau, la qual havia novament construhida, en la plaja de Barchinona, entre lo abeurador de la Lotja e la Font del Ângel de la Fustaria, e trigà's a verar XXXXII dies continuus, que prou penjats van a la forcha pus tost que no feya ella a $\operatorname{mar}^{56}$.

És simptomàtic i fa una certa gràcia que Jaume Safont, el redactor del Dietari, afirmi que és més ràpid penjar un home a la forca que varar una nau. La varada d'una nau no només era complexa i necessitava d'una gran quantitat d'homes per a facilitar la seva varada, sinó que tant el vaixell com l'operació creava una gran expectació, amb un munt de gent observant l'espectacle, quedant aquesta documentada als dietaris.

\subsubsection{El banquet de la varada}

En el cas de la nau grossa Sant Miquel Arcàngel de Sant Feliu de Guíxols, aquesta es varà la setmana després de ser beneïda. El diumenge 14 de juliol de 1448 fou el dia de la varada. Tot estava llest, la gent també i el temps era bo. Es feren quatre misses, per 5 sous, i començà l'operació de varada de la nau. Sembla que tot anà bé, acabada la feina es féu un dinar per a tot el personal que havia participat en la varada, amb el consum de 34 bótes collereses de vi vermell, 2 bótes collereses de vi blanc, una bóta de vi blanc, 6 bótes collereses de vi francès, 216 lliures de carn de bou, 66 lliures de carn

\footnotetext{
${ }^{54}$ Barker 2003, pp. 102-170.

${ }^{55}$ Pintures de la vida de Santa Úrsula de Vittore Carpaccio, finals del segle XV (Galleria dell'Academia, Venècia).

${ }^{56}$ Sans 1994, vol. I, p. 131.
} 
de vedell, carbasses, canyella i fruita, a més dels deu parells de pollastres que s'havien comprat dies abans.

\subsection{L'arborar}

En molts casos, sobretot en els vaixells grans, aquests s'arboraven un cop el buc havien estat varats. A les embarcacions petites i mitjanes, fins i tot a les galeres l'operació d'arborar era bastant similar i molt menys complexe. $\mathrm{Si}$ aquestes arboraven vela llatina solien tenir un arbre i una antena per arbre, des de les barques de pesca amb un sol arbre fins a les galeres més grans o els xabecs que en podien dur tres. En canvi a les naus baixmedievals i vaixells similars de l'Era Moderna (galions, navilis, fragates, corbetes) amb un aparell mixt, amb un mínim de tres arbres, i aquests alhora dividits en una successió d'arbres superposats, amb diferents antenes i veles també superposades, l'operació d'arborar era enormement complexe, no només per la quantitat de pals (arbres i antenes) sinó pels caps i talles de l'eixàrcia ferma i de treball.

Un bon exemple torna a ser la nau grossa Sant Miquel Arcàngel construïda pel rei a Sant Feliu de Guíxols entre els anys 1446 i 1448, la qual s'arborà a principis de setembre del 1448 -gairebé dos mesos després de ser varada- ${ }^{57}$.

Per una banda es va anar a Girona el 4 de setembre a buscar el veguer perquè gaudís de l'espectacle d'arborar la nau i alhora a demanar al bisbe llicència -concedida el 6 de setembre- per a poder treballar el diumenge dia 8 , quan es pretenia arborar la nau grossa:

En Bernat, per la miseració divinal bisbe de Gerona, als discrets e amats nostres lo capellà o rector de la vila de Sanct Feliu de Guíxols e altres rectors de les sglésies de la vila de Palamors e d'altres llocs vehinables a la dita vila de Sanct Ffeliu, saluts en nostre Senyor. Sapiats que lo dia present som stats certifficats per lo patró de la nau grossa del senyor rey fabricada en lo port de la dita vila de Sanct Ffeliu que digmenge pus prop vinent, que comptarem VIII del present mes de satembra, ell dit patró farà mitgensant lo adjutori de Déu arborar la dita nau, e assò per la necessitat de fustes armades de enamichs del dit senyor rey qui trastegen en aquestes mars, dels quals la dita nau pus fàcilment serà deffesa arborada que no sens arbra. E nós, a soplicació humil del dit patró, occorrents a la dita necessitat e dant camí a tant necessària obra, confiants de la misericòrdia de Déu, dispensam per aquesta vegada que totes aquelles persones qui de neces-

\footnotetext{
${ }^{57}$ A Gènova, l'any 1546, la nau Santa Maria Bertorota, de dues cobertes i 27,5 m de llargada de roda a roda, el termini de construcció fou d'un any, en canvi un cop es vara tardaren quatre mesos en arborar-la. Gatti 1975a, p. 43; Borghesi, Calegari 1970, pp. 93-116.
} 
sitat hauran manualment obrar la dita jornada per lo dit negoci /f $72 \mathrm{v} /$ puxen lavorar e treballar en spatxament del dit arborament sens incorriment de peccat mortal. E encare a tots e sengles faels christians ajudants en lo dit negoci la dita jornada, nós de gràcia special donam .XL. dies de perdó, menants a vosaltres en virtut de sancta obediència e sots pena de vet que les dites presents nostres letres publiquets e intimets als pobles a vosaltres comenats e aquells induhits a socórrer al dit negoci e gonyar la dita nostra indulgència, considerada la necessitat damunt dita. E dessó haurets mèrit e.n farets a nós servei singular. Dade en Gerona a .VI. del mes de satembra en l'any de la nativitat de nostre senyor Déus Jhesuchrist .MCCCCXL. vuyt ${ }^{58}$.

El diumenge 8 de setembre de 1448 s'arborà la nau ${ }^{59}$. Sembla que la nau s'acostà a la platja, es col·locaren bótes per amortir el buc contra la platja i amb les càbries aixecaren els arbres i els posaren tots tres al seu lloc. El gran pes i la dificultat de manipular els arbres féu necessari també molta mà d'obra, tornant a demanar a gent de fora de la vila que hi vingués a ajudar, homes de Lloret i de Blanes tornen a anar-hi a treballar.

Aquest mateix dia es celebrà el banquet de l'arborar, consumint-se peix per nau ont menjà gent que havie vingut per l'arborar, es donaren ous a la gent de Lloret, 140 lliures de carn de bou, 26 lliures de carn de vedell, confits de sucre, 16 bótes collereses de vi vermell, vi grec, 1 bóta colleresa de vi blanc, canyella, mostassa i fruita. I finalment en el llibre de comptes consta que l'11 de setembre es pagà el lloguer del vidre que havia servit per a les cerimònies del romball, de beneir, de varar i d'arborar.

Acabada i arborada, llesta per a navegar la nau grossa Sant Miquel Arcàngel, fou amarinada, armada i proveïda, tot salpant a finals de l'any 1448 cap a Eivissa, i després cap a Nàpols on seria rebuda pel rei Alfons el Magnànim ${ }^{60}$.

\section{EN CONCLUSIÓ}

A l'Edat Mitjana el nom d'una embarcació es decidia en el moment en que se n'acordava la construcció entre l'armador i el mestre d'aixa, fos per escrit o de paraula. A partir del moment que aquest iniciava la seva construcció fins a la seva varada tenien lloc una sèrie de banquets i cerimònies lligades a les diferents fases constructives. La primera de totes tenia lloc al començar a

\footnotetext{
${ }^{58}$ ADG, Lletres episcopals. U (1334-1620), vol. 148, f. 72. Marquès 1992, p. 11, ap. 2.

${ }^{59} \mathrm{ACA}, \mathrm{RP}, \mathrm{MR} 2334$, f. $75 \mathrm{r}$. El diumenge 8 de setembre "ab lo nom de Déu arborà la beneyta nau".

${ }^{60}$ ACA, Cancelleria, 2719 i 2895.
} 
preparar l'indret on es construiria, l'escar, on els mestres d'aixa ho celebraven bevent vi o fent-hi un àpat. En algún cas els representants de les institucions promotores de la construcció de galeres practicaven l'acte simbòlic de clavar un clau a l'estepa (la base de l'estructura del buc a construir). La segona celebració més important era coneguda com la festa del romball, practicada a l'acabar de folrar el buc, en que de nou els mestres d'aixa celebraven un dinar. Una vegada els calafats havien impermeabilitzat el buc i estava llesta per a ser varada podien celebrar-se tres rituals consecutius, el primer de caràcter religiós, consistia en la benedicció de l'embarcació, per la qual es celebrava l'acte al costat si era una embarcació menor o a dalt de la coberta si era una nau o una galera, acabat l'acte els armadors institucionals podien regalar una copa daurada al mestre d'aixa major i al mestre calafat major respectivament, i aquests a canvi regalaven les seves eines (l'aixa i el marc), llavors els mestres es retiraven a celebrar-ho amb un bon dinar. La quarta etapa era la varada, enormement complexa en el cas de les naus, que també es celebrava amb un àpat, i en el cas de les naus també es podia celebrar la festa de l'arborar a l'acabar de muntar els pals, les antenes i tota l'eixàrcia.

\section{GLOSSARI}

Anap: copa d'argent daurada.

Buc: el cos d'una embarcació.

Carena: element longitudinal base del buc d'una embarcació, l'equivalent a l'actual quilla.

Cinta: element longitudinal extern que ressegueix a cada banda del buc i per sobre de la línia de flotació.

Corbam: peces de fusta de formes corbades, adients per a fer madissos, estameneres i rodes.

Dragant: element transversal, posat per sobre del timó, que aguanta tota l'estructura de popa.

Eixàrcia: conjunt de caps d'una embarcació.

Escala de varar: conjunt de parats o peces de fusta que formen la base per la qual llisca l'embarcació des de l'escar fins al mar.

Escar: lloc on el mestre d'aixa construeix o repara una embarcació.

Escoa: 1. Element longitudinal exterior que forma part del folre, però sovint endentat $i$ clavat a les quadernes i unit a elements longitudinals interiors mitjançant cavilles de fusta o perns de ferro. 2. Punt de la secció transversal on s'ajunta el pla amb el costat d'una embarcació.

Esquif: l'embarcació auxiliar més petita de naus i galeres. 
Estamenera: element que forma el costat d'una quaderna.

Estepa: a l'escar es tracta d'un conjunt de peces de fusta que actuen de base de la construcció, sobre el qual s'asseu la carena.

Goa: unitat de mesura de longitud, típicament naval, utilitzada a tota la Mediterrània Occidental, i que equivalia a la Catalunya medieval a $64,79 \mathrm{~cm}$.

Jornal: el salari diari que cobrava un mestre d'aixa a la segona meitat del segle XIV i al XV era de 3 lliures, mentre el d'un fadrí o aprenent de mestre d'aixa era de 2 sous i 6 diners.

Lliura de carn: la lliura comú equivalia a $0,396 \mathrm{Kg}$, mentre que la lliura carnissera era de $1,2 \mathrm{Kg}$.

Lliures, sous $i$ diners: unitats de compte d'origen carolingi, utilitzat a Catalunya durant l'Edat Mitjana i Moderna. La lliura equivalia a 20 sous o 240 diners.

Madís: element que forma el pla d'una quaderna.

Marc: 1. Martell petit que utilitza el calafat. 2. Unitat de pes equivalent a $230 \mathrm{~g}$.

Pam de goa: la tercera part d'una goa, per tant 21,59 cm.

Paramitjal: element longitudinal que ressegueix per l'interior del buc a la carena.

Paramola: forat o estructura que és la base en la que s'insereix l'arbre.

Quaderna: element transversal que forma la costella de l'esquelet del buc d'una embarcació.

Quaderna mestra: de totes les quadernes, la més ampla i alta, que es sol situar a la part central del buc.

Roda de proa i de popa: elements corbats que formen part de l'eix longitudinal del buc, situat un a proa i l'altra a popa.

Romball: l'última peça o tros de taula que completa el folre del buc.

Timó: element de direcció de l'embarcació.

Timonera: element de subjecció dels timons laterals.

Vasos: peces de fusta que es posen a banda i banda del buc, per sobre de l'escala de varar, lligats entre ells amb cordes. La seva funció és sostenir el buc i lliscar per sobre de l'escala de varar fins al mar.

\section{BIBLIOGRAFIA CITADA}

Amades i Gelats, Joan (1950), Folklore de Catalunya: I. Rondallística. Tradicions. Llegendes, Barcelona, Selecta Catalana.

Balbi, Giovanna (1966), I nomi di nave a Genova nei secoli XII e XIII, dins Miscellanea di Storia Ligure in memoria di G. Falco, Genova, [s.n.], pp. 65-86. 
Barker, Richard (2003), Cradles of navigation re-visited, dins Nowacki, Horst; Valleriani, Matteo (eds.), Shipbuilding Practice and Ship Design Methods from the Renaissance to the $18^{\text {th }}$ Century, Berlin, Max Planck Institute for the History of Science, pp. 101-170.

La Bíblia. Bíblia catalana, traducció interconfessional (2008), Barcelona Associació Bíblica de Catalunya - Editorial Claret - Societats Bíbliques Unides.

Borghesi, Vilma; Calegari, Manlio (1970), La nave Bertorota (1547-1561), dins Guerra e comercio nell'evoluzione della marina genovese tra XV e XVII secolo, Gènova, Il Centro, pp. 93-116

Bresc, Geneviève; Bresc, Henri (1979), Les saints protecteurs de bateaux, 1200-1460, "Ethnologie française" 9/2, pp. 161-178.

Bresc, Henri (1981), La pieté des gens de mer en Mediterranée occidentale aux derniers siècles du Moyen-Age, dins Ragosta, Rosalba (ed.), Le genti del mare Mediterraneo, Nàpols, Pironti, vol. I, pp. 427-443.

Capmany, Antonio de (1787), Ordenanzas de las Armadas Navales de la Corona de Aragón, aprobadas por el rey d. Pedro IV, año de MCCCLIV, Madrid, Imprenta Real.

Capmany y de Montpalau, Antonio de (1961-1963), Memórias históricas sobre la marina, comercio y artes de la antigua ciudad de Barcelo$n a$, reedició anotada i revisada per Giralt i Raventós, Emili; Batlle i Gallart, Carmen, 3 vols., Barcelona, Cámara Oficial de Comercio y Navegación de Barcelona [4 vols., Madrid, 1779-1792].

Carreras y Candi, Francesch; Schwartz y Luna, Federico (eds.) (1892), $M a$ nual de novells ardits vulgarment apellat Dietari del Antich Consell Barceloní, 28 vols. Barcelona, Henrich y companyia.

Carrère, Claude (1977-1978), Barcelona 1380-1462. Un centre econòmic en època de crisi, 2 vols., Barcelona, Curial (Documents de cultura; 11). Traduït per Hermínia Grau de Duran, Barcelone, centre économique à l'époque des difficultés (1380-1462), 2 vols. Paris-La Haye, Mouton.

Checa, Francisco; Molina, Pedro (1997), La función simbólica de los ritos. Rituales y simbolismos en el Mediterráneo, Barcelona, Instituto de Estudios Almerienses.

Coll i Julià, Núria (1988), Noms de galeres catalanes del segle XV, "Butlletí Interior. Societat d'Onomàstica" 32, pp. 35-40.

Colon, Germà; García, Arcadi (eds.) (1981-1987), Llibre del Consolat de Mar, 5 vols., Barcelona, Fundació Salvador Vives Casajoana - Fundació Noguera.

Duran i Sanpere, Agustí; Sanabre, Josep (eds.) (1930-1947), Llibre de les Solemnitats de Barcelona. Edició completa del manuscrit de l'Arxiu Històric de la Ciutat, 2 vols., Barcelona, Institució Patxot. 
Estrada-Rius, Albert (2004), La Drassana Reial de Barcelona. Organització institucional i construcció naval a la Corona d'Aragó, Barcelona, Museu Marítim de Barcelona.

Ferreira Priegue, Elisa (1994), Benedictio navis novae. Aportaciones al estudio de las celebraciones en torno a la construcción y botadura del buque en la Edad Media y Moderna, "Semata, Ciencias Sociais e Humanidades" 6, pp. 159-171.

Fuente de Pablo, Pablo de la; Pujol i Hamelink, Marcel (2010), La Reial Fàbrica de Vaixells de Sant Feliu de Guíxols (1715-1721), Sant Feliu de Guíxols, Ajuntament de Sant Feliu de Guíxols.

Garcia i Sanz, Arcadi; Coll i Julià, Núria (1994), Galeres mercants catalanes dels segles XIV $i \mathrm{XV}$, Barcelona, Fundació Noguera.

Garrido Escobar, Alfons (2006), Pesca i associanisme al litoral de Girona: La confraria de Sant Pere de Palamós (segles XVII-XVIII), Girona, Universitat de Girona (treball de DEA).

Gatti, Luciana (1975a), Costruzioni navali in Liguria fra XV e XVI secolo, dins Studi di Storia Navale, Florència, Giunti-Barbera, pp. 25-72.

Gatti, Luciana (1975b), Imbarcazioni ragusee nel secolo XVI, dins Studi di Storia Navale, Florència, Giunti-Barbera, pp. 73-96.

Gatti, Luciana (1999), Navi e cantieri della Repubblica di Genova (secoli XVI-XVIII), Gènova, Brigati.

Gatti, Luciana (2004), Catene d'oro per il maestro Ambroggio. Costruttori di navi tra medioevo ed età moderna nelle fonti notarili genovesi, dins Saper Fare: Studi di storia delle techniche in área Mediterranea, Pisa, ETS, pp. 51-84.

Gatti, Luciana (2008), Un raggio di convenienza. Navi mercantili, costruttivi e propietari in Liguria nella prima metà dell'Ottocento, Gènova, Società Ligure di Storia Patria.

Guérout, Max; Rieth, Eric; Gassend, Jean Marie (1989), Le navire génois de Villefranche. Un naufrage de 1516?, Paris, CNRS (Archaeonautica; 9).

Jaume I, Crònica o Llibre dels Feits, a cura de Ferran Soldevila, Barcelona, Edicions 62, 1994 (MOLC; 86).

Julià i Figueres, Benet (1985), La drassana reial de Sant Feliu de Guíxols, "Revista de Girona" 111, pp. 160-163.

Lo Basso, Luca (2004), La costruzione della nave 'Nostra Signora dell'Apparizione e S. Pietro' (Savona, 1671-73), dins Saper Fare: Studi di storia delle techniche in área Mediterranea, Pisa, ETS, pp. 85-125.

Marquès i Planagumà, Josep Maria (1992), Benediccions de barques (13911594), "Estudis del Baix Empordà" 13, pp. 5-11. 
Martínez San Martín, Petri (1840), Rituale ecclesiae et dioecesis barcinonenses ad normam ritualis romani. Auctum, correctum et emendatum, Barcelona, Heredum Viduae Pla.

Mollat, Michel (1979), Les attitudes des gens de mer devant le danger et devant la mort, "Ethnologie Française" 9/2, pp. 191-200.

Muntaner, Ramon, Crònica, a cura de Marina Gustà, 2 vols., Barcelona, Edicions 62, 1991-1994 (MOLC; 19 i 20).

Ortega Villoslada, Antonio (2015), La marina mercante medieval y la Casa de Mallorca: entre el Mediterráneo y el Atlántico, Lleida, Pagès.

Pujol i Hamelink, Marcel (2012), La construcció naval a la Corona d'Aragó. Catalunya (segles XIII-XV), Barcelona, Base.

Puñal Fernández, Tomàs (2002), Análisis documental de los rituales de posesión en la Baja Edad Media, "Espacio, Tiempo y Forma. Serie III. Historia Medieval" 15, pp. 113-148.

Sans i Travé, Josep Maria (dir.) (1994), Dietaris de la Generalitat de Catalunya (1411-1714), 10 vols., Barcelona, Generalitat de Catalunya.

Sastre Moll, Jaime (1994), El puerto de la Ciutat de Mallorca durante el reinado de Sancho y la regencia de Felipe de Mallorca (1311-1330). Rentas reales portuarias y su reinversión, "Miscel-lània de Textos Medievals" 7,pp. 141-151.

Fecha de recepción del artículo: mayo 2016

Fecha de aceptación y versión final: marzo 2017 